\title{
VULNERACIÓN DE MARCAS DE LA UNIÓN EUROPEA EN INTERNET Y DERECHO INTERNACIONAL PRIVADO
}

\author{
INFRINGEMENT OF EUROPEAN UNION TRADE MARKS \\ ON THE INTERNET AND PRIVATE INTERNATIONAL LAW
}

\author{
ISABEL LORENTE MARTÍNEZ \\ Profesora asociada de Derecho internacional privado \\ Universidad de Murcia \\ Universidad Miguel Hernández \\ Abogada ejerciente
}

Recibido: 06.04.2020 / Aceptado: 04.05.2020

DOI: https://doi.org/10.20318/cdt.2020.5654

\begin{abstract}
Resumen: Con la atención puesta en la reciente sentencia del TJUE de 5 septiembre 2019 en este trabajo se hace un análisis de las cuestiones de Derecho internacional privado pertinentes en relación con la vulneración de la marca europea en un contexto internacional. Se observa en particular el pronunciamiento del TJUE en relación con la competencia judicial internacional, en relación con el foro especial por razón de la materia del art. 7.2 del Reglamento Bruselas I bis.

Palabras clave: marca europea, competencia judicial internacional, ley aplicable, vulneración, Internet.

Abstract: With the attention given to the recent judgment of the CJEU of 5 September 2019 this work makes an analysis of the issues of private international law relevant with regard to the infringement of the European trade mark in an international context. The Court of Justice has issued a judgement on international jurisdiction in connection with the special ground on the subject as declared in Art. 7.2 of the Brussels I bis Regulation.
\end{abstract}

Keywords: European trademark, international jurisdiction, applicable law, infringement, Internet.

Sumario: I. Introducción. II. Mercado interior europeo y derechos de propiedad intelectual e industrial en el Derecho Internacional Privado. III. Vulneración de marca en Internet y mercado único. 1. Competencia judicial internacional. 2. Ley aplicable. IV. Conclusiones.

\section{Introducción}

1. A propósito de la STJUE 5 septiembre 2019, C-172/18, AMS Neve Ltd, Barnett Waddingham Trustees, Mark Crabtree vs. Heritage Audio, S.L., Pedro Rodriguez Arribas [ECLI:EU:C:2019:674] surgen cuestiones relativas a la marca de la Unión Europea que viene a despejar con atino el TJUE. Es en relación con el foro especial por razón de la materia, artículo 7.2 del Reglamento Bruselas I bis, donde surgen dudas, que resuelve de un forma clara el Tribunal de Justicia de la Unión Europea ${ }^{1}$. En relación

\footnotetext{
${ }^{1}$ Artículo 7.2 del Reglamento Bruselas I bis:

"Una persona domiciliada en un Estado miembro podrá ser demandada en otro Estado miembro:

2) en materia delictual o cuasidelictual, ante el órgano jurisdiccional del lugar donde se haya producido o pueda producirse el hecho dañoso;"
} 
con la explicación de la competencia judicial internacional en este tema, qué mejor forma de hacerlo que analizar en profundidad lo que el Tribunal de Justicia de la Unión Europea, no sin antes observar las razones que conducen a esta problemática y la búsqueda de su solución.

\section{Mercado interior europeo y derechos de propiedad intelectual e industrial en el Derecho Inter- nacional Privado}

2. Es fundamental recordar que con la Unión europea se cimentó y construyó un "mercado interior" cuyos fundamentos primigenios son las tradicionales "libertades de circulación" propias de la Unión Europea. El artículo 26.2 del TFUE define el "mercado interior":

El mercado interior implicará un espacio sin fronteras interiores, en el que la libre circulación de mercancías, personas, servicios y capitales estará garantizada de acuerdo con las disposiciones de los Tratados.

3. Por lo tanto, es el propio Derecho de la Unión Europea el que directa y tajantemente prohíbe los obstáculos a esas libertades de circulación, y de ese modo se expone en el Título IV del TFUE. La abolición de esos obstáculos es general, ya sean de Derecho público (ad ex.: contingentes y topes de importación y exportación de mercancías, aranceles aduaneros, necesidad de permisos de residencia y trabajo) o de Derecho privado (cada Estado miembro tiene sus propias normas de Derecho Privado y sus propias normas de Derecho internacional privado, eso no puede perjudicar las libertades de circulación). De este modo lo ha dejado patente el TJUE en numerosa jurisprudencia ${ }^{2}$, tal como exponen los profesores Calvo y Carrascosa ${ }^{3}$.

4. El legislador de la Unión Europea ha elaborado una ingente cantidad de normas en relación con el régimen jurídico de la propiedad intelectual e industrial, sobre todo, Directivas que contemplan aspectos sustantivos de estos derechos. Esos aspectos de fondo que contienen las Directivas se incorporan al Derecho nacional de cada Estado miembro, como bien es sabido.

5. Con carácter previo, se debe resaltar que estos derechos de propiedad intelectual e industrial son "derechos territoriales". Esta cualidad que llevan adherida estos derechos es crucial para comprender la particularidad de los mismos. Esto significa que son derechos concedidos por un determinado Estado cuya protección se extiende únicamente para el territorio de ese Estado. Son las normas jurídicas de ese Estado miembro las que deciden si se otorga o no esa protección a la patente, diseños, marca, dibujos, etc. Y es esta cuestión, la relativa a la territorialidad de estos derechos que suscita ciertos inconvenientes si se relaciona con la idea de "mercado único" europeo apuntada con anterioridad. El sujeto que es titular de un derecho inmaterial dispone de una facultad de exclusión o prohibición de ese derecho frente a todos los que no son titulares de ese derecho en cuestión ${ }^{4}$. De este modo, el "mercado interior"

2 STJCE 30 marzo 1993, Konstantinidis, ECLI:EU:C:1993:115; STJCE 2 diciembre 1997, Dafeki, ECLI:EU:C:1997:579; STJCE 23 noviembre 2000, Elsen, ECLI:EU:C:2000:647; STJCE 9 marzo 1999, Centros, ECLI:EU:C:1999:126; STJCE 5 noviembre 2002, Überseering, ECLI:EU:C:2002:632; STJCE 30 septiembre 2003, Inspire Art, ECLI:EU:C:2003:512; STJCE 2 octubre 2003, García Avello, ECLI:EU:C:2003:539; STJUE 14 octubre 2008, Grunkin- Paul, ECLI:EU:C:2008:559; STJUE 22 diciembre 2010, as. C-208/09, Wittgenstein, ECLI:EU:C:2010:806; STJUE 12 mayo 2011, as. C-391/09, Vardyn; ECLI:EU:C:2011:291; STJUE 2 junio 2016, C-438/14, Bogendorff, ECLI:EU:C:2016:401; STJUE 8 junio 2017, C-541/15, Freitag, ECLI:EU:C:2017:432,

3 Vid. A.-L. Calvo caravaca/J. Carrascosa González, Derecho internacional privado, vol. I, 18 a ed., Ed. Comares, Granada, 2018, p. 95.

${ }^{4}$ Artículo 63 de la Ley 11/1986, de 20 de marzo, de Patentes: "1. El titular cuyo derecho de patente sea lesionado podrá, en especial, solicitar: a) La cesación de los actos que violen su derecho."

Artículo 34 de la Ley 17/2001, de 7 de diciembre, de Marcas: "1. El registro de la marca confiere a su titular el derecho exclusivo a utilizarla en el tráfico económico.

2. El titular de la marca registrada podrá prohibir que los terceros, sin su consentimiento, utilicen en el tráfico económico (...)”. 
se ve dañado por la protección nacional de esos derechos, ya que existen barreras jurídicas nacionales a la libre circulación, que son esos derechos nacionales de propiedad intelectual e industrial ${ }^{5}$.

6. La solución que adoptó en su momento el TJCE para evitar el perjuicio que se le podría producir al "mercado interior", fue la elaboración de la doctrina del "agotamiento comunitario" de los derechos inmateriales nacionales (First Sale Doctrine). Así lo ha expuesto en su jurisprudencia el TJCE'. La doctrina del "agotamiento comunitario" esto puede sintetizarse tal como destacan Calvo y Carrascosa, muy brevemente, en lo siguiente: cuando una mercancía protegida por derechos de propiedad intelectual o industrial ha sido vendida en la Unión Europea por el titular del derecho de propiedad intelectual, o por un tercero con el consentimiento expreso o tácito, del titular, entonces es lícita la ulterior distribución del producto en la Unión Europea. El derecho del titular de la propiedad industrial o intelectual, a "poner en circulación en la Unión Europea" el producto protegido se ha "agotado" con esa primera puesta en circulación del producto en la Unión Europea?

7. Las ventajas que comporta la doctrina del "agotamiento comunitario" sobre estos derechos es de vital importancia. Esta doctrina creada por el TJCE evita los perjuicios que supondrían estos obstáculos, creados por los Derechos nacionales y que derivan del principio de territorialidad de los derechos inmateriales, sobre la libre circulación de mercancías en el mercado interior.

\section{Vulneración de marca en Internet y mercado único}

8. Las nuevas tecnologías han venido a transformar nuestro día a día. En este momento, es relativamente sencillo encontrar servicios en la web, empresas especializadas en determinados sectores comerciales que operan a nivel mundial. La arquitectura del mundo ha cambiado con Internet, y esto provoca que se planteen nuevos y apasionantes retos para los juristas del Siglo XXI.

9. En la actualidad, los bienes inmateriales han alcanzado una extraordinaria importancia. Se puede afirmar que las propiedades inmateriales (= marcas, patentes, derechos de autor, derechos de copyright, ideas, acciones, know-how, etc.) mueven mucha más riqueza que las propiedades materiales (= casas, coches, barcos, joyas, etc.) El logro de los "juristas alquimistas" ha sido, precisamente, crear valor de la nada, crear riqueza desmaterializada, invisible, intangible, pero real, riqueza elevada a puro concepto ${ }^{8}$. La determinación de los tribunales que son competentes para conocer de cualquier asunto relativo a estas propiedades inmateriales, así como la determinación del Derecho nacional aplicable a esos litigios, son muy complejas de determinar, por la especialidad y valor que tienen estos bienes inmateriales.

10. Las dificultades que suscitan este tipo de bienes inmateriales (en este trabajo, con especial énfasis se trata el tema de las marcas) aumentan por los retos que nos plantea un mundo globalizado. En la actualidad y con la facilidad de comunicaciones existente, una marca puede ser explotada en todo el mundo al mismo tiempo (Worldwide Explotation). Además de otro dato a subrayar en relación a este tipo de bienes: se trata de derechos que no recaen sobre una cosa física. Con los derechos reales sobre bienes corporales se utiliza el punto de conexión del "lugar de situación de la cosa". Ese punto de conexión se hace inoperativo con los bienes inmateriales, ya que son "derechos de exclusiva" o "monopolios de explotación", personales y patrimoniales, oponibles frente a terceros, es decir, son derechos oponibles erga omnes.

${ }^{5}$ Vid. A.-L. Calvo caravaca/ J. Carrascosa González, Derecho internacional privado, vol. II, $18^{a}$ ed., Ed. Comares, Granada, 2018, pp. 1113-1114.

${ }^{6}$ STJCE 31 de octubre 1974, Centrafarm vs. Sterling, STJCE 31 de octubre 1974, Centrafarm vs. Winthrop, STJCE 8 de junio 1971, Deutsche Grammophon.

7 A-L Calvo caravaca/J. Carrascosa González, Derecho internacional privado, vol. II, $18^{\mathrm{a}}$ ed., Ed. Comares, Granada, 2018, pp. 1243-1244.

${ }^{8}$ Vid. A.-L. Calvo caravaca /J. Carrascosa González, Derecho internacional privado, vol. II, 18 a ed., Ed. Comares, Granada, 2018, p. 1086. 
11. En los siguientes epígrafes se explora la cuestión relativa a la competencia de los tribunales para conocer de los supuestos internacionales de usurpación de marca, de los nuevos retos que se plantean con Internet. Igualmente, se expondrá la cuestión de la determinación de la Ley reguladora de estos derechos incorporales. Se debe señalar que en este punto se trata la cuestión de la usurpación de una marca, esto es, un daño, que permite que se pueda demandar en base a una responsabilidad extracontractual, de forma alternativa al foro del domicilio del demandado. Y en relación con la Ley aplicable, es la misma cuestión la que se despeja: la Ley aplicable a la usurpación de la marca. Por lo tanto, esta no es materia cubierta por el foro exclusivo previsto en el artículo 24 del Reglamento Bruselas I bis, y en relación con la Ley aplicable los litigios por vulneración de marca se rigen por un específico instrumento legal, que se analizará en su punto.

\section{Competencia judicial internacional}

12. El instrumento legal que determina qué tribunales son los competentes para conocer en este caso es el Reglamento ${ }^{\circ}$ 1215/2012 del Parlamento Europeo y del Consejo de 12 de diciembre de 2012 relativo a la competencia judicial, el reconocimiento y la ejecución de resoluciones judiciales en materia civil y mercantil (refundición) (Bruselas I bis, en adelante RB I bis). El foro general del domicilio del demando, previsto en el artículo 4 de dicho Reglamento 9 , opera sin problemas. Es en relación con el foro especial por razón de la materia, artículo 7.2 del Reglamento Bruselas I bis, donde surgen dudas, como ya se ha apuntado. Y esas dudas son las que resuelve de una forma clara el Tribunal de Justicia de la Unión Europea. En relación con la explicación de la competencia judicial internacional en este tema, qué mejor forma de hacerlo que analizar en profundidad lo que el Tribunal de Justicia de la Unión Europea dice al respecto, en su ya célebre sentencia de 5 de septiembre de 2019 C-172/18.

13. La reciente STJUE de 5 de septiembre de 2019 viene a dar respuesta a una cuestión bastante tratada, como se ha observado, en el ámbito de las demandas interpuestas por infracción de la marca europea cometida en Internet. El TJUE interpreta y aporta nuevas perspectivas sobre el forum delicti commissi. Foro especial por razón de la materia contenido en el artículo 7.2 del Reglamento Bruselas I bis.

14. Los datos fácticos del caso se resumen como sigue: la empresa británica AMS Neve interpone una demanda ante los tribunales ingleses contra la empresa española Heritage Audio. El contenido de esa demanda era por una infracción de la marca británica y europea que AMS Neve creía que se habían infringido en el Reino Unido, puesto que Heritage Audio ofrecía sus productos a través de su sitio web en dicho mercado. AMS Neve mantenía que esos productos infringían su marca en el mercado británico. Con este escenario apuntado el tribunal inglés se declaró competente para conocer de la demanda ex foro especial por razón de la materia del art. 7.2 del Reglamento Bruselas I-bis. Existe jurisprudencia del TJUE ${ }^{10}$ que expone que el simple hecho de que la marca esté registrada en un país es suficiente para que los tribunales puedan declarase competente en base al forum delicti commissi: Esto cumple con los objetivos del propio Reglamento Bruselas I bis de previsibilidad y buena administración de la justicia ${ }^{11}$.

\footnotetext{
${ }^{9}$ Artículo 4 del Reglamento Bruselas I bis:

"I. Salvo lo dispuesto en el presente Reglamento, las personas domiciliadas en un Estado miembro estarán sometidas, sea cual sea su nacionalidad, a los órganos jurisdiccionales de dicho Estado.

2. A las personas que no tengan la nacionalidad del Estado miembro en que estén domiciliadas les serán de aplicación las normas de competencia judicial que se apliquen a los nacionales de dicho Estado miembro."

${ }^{10}$ STJUE de 19 de abril de 2012, Wintersteiger, [ECLI:EU:C:2012:220], ap. 27: "En cuanto a la competencia para conocer de una acción por vulneración de una marca nacional en un supuesto como el del procedimiento principal, procede considerar que tanto el objetivo de previsibilidad como el de buena administración de justicia militan en favor de la atribución de competencia, atendiendo al criterio de la producción del daño, a los tribunales del Estado miembro en que se halla protegido el derecho en cuestión."

${ }^{11}$ A. Dickinson-E. Lein, The Brussels I Regulation Recast, Ed. Oxford, 2015, pp. 170-171.
} 
15. Pero el escollo lo encuentra el tribunal inglés en su competencia para conocer en relación con las marcas UE. Puesto que para estos litigios la competencia se establece en virtud de lo que expone el párrafo 5 del art. $125 \mathrm{RMUE}^{12}$. El juez inglés estimó que la infracción de la marca europea se había producido en España, y no podía entrar a conocer de la misma. El resultado de esta interpretación es ineficaz para el particular que debe litigar por este asunto, porque por la infracción de marca UE y de marca nacional debe acudir a foros distintos, a no ser que se den los requisitos que establece el TJUE y que a continuación se observarán con mayor detenimiento. La divergencia entre el foro previsto en el art. 7.2 del Reglamento Bruselas-I bis y el art. 125.5 RMUE conduce en ciertos casos a litigar en países diferentes si se ostenta la marca UE. Según lo previsto en el art. 67 del Reglamento Bruselas-I bis, este Reglamento no prejuzgará la aplicación de las disposiciones que regulan la competencia judicial internacional en materias particulares contenidas en los actos de la Unión o en las legislaciones nacionales armonizadas en ejecución de dichos actos ${ }^{13}$.

16. El TJUE realiza una interpretación en este sentido en el apartado 56 de la sentencia que se comenta:

“... si de los contenidos del sitio web y de las redes controvertidos [...] se desprende que la publicidad y las ofertas de venta que incluian estaban destinadas a consumidores o distribuidores situados en el Reino Unido, para los que resultaban plenamente accesibles, [...] los mencionados demandantes dispondrán de la facultad de interponer, sobre la base del artículo [125], apartado 5, [...] su acción por violación de marca ante un órgano jurisdiccional del Reino Unido, con el fin de que se declare la existencia de una violación de la marca de la Unión en dicho Estado miembro".

17. Este importante apartado lo que determina es que el Tribunal establece el criterio de la focalización para determinar la competencia del tribunal. Las actividades dirigidas a ese mercado son el dato determinante para que un tribunal se declare competente para conocer de una infracción de un derecho de propiedad intelectual por el forum delicti commissi. Se debe probar que el presunto infractor dirigía sus actividades a ese Estado y además que en ese Estado se encuentran consumidores o distribuidores.

18. Sin duda alguna, este criterio que aporta el TJUE respeta el principio de previsibilidad jurídica y evita que una empresa pueda ser demandada por una infracción de marca simple y llanamente porque se pueda acceder a su sitio web desde un determinado Estado, esto es, porque se constate el criterio de la accesibilidad, que es el que contempla el art. 7.2 del Reglamento Bruselas I-bis.

19. Pese a este paso dado por el TJUE sigue existiendo esa dispersión competencial según sea el objeto del litigio, marca nacional o marca UE, porque como se indicaba el art. 7.2 del Reglamento Bruselas I-bis sigue manteniendo el peligroso criterio de la mera accesibilidad, es decir, el simple hecho de que el sitio web es accesible desde el Estado miembro donde está registrada la marca nacional es suficiente para que el tribunal pueda declararse competente.

20. En realidad, el texto del art. 125.5 del RMUE no apunta nada en relación con los consumidores, tal como se puede observar, tampoco del texto de este artículo se extrae la tesis de la focalización. En el art. 7.2 del RB I bis tampoco se observa la precitada tesis. Y a continuación se exponen los textos de ambos artículos, donde se puede observar que la dicción literal de uno u otro no dista tanto, en relación con el enfoque que finalmente le da el TJUE a la interpretación que hace del art. 125.5 del RMUE en la sentencia que se estudia en este trabajo.

\footnotetext{
${ }^{12}$ Reglamento 2017/1001 del Parlamento europeo y del Consejo de 14 de junio de 2017 sobre la marca de la Unión Europea. DOUE L $154 / 55$.

${ }^{13}$ En relación con esta cuestión se puede consultar el Comentario al art. 67 del Reglamento Bruselas I bis, de A. Poch ToRT en Comentario al Reglamento (UE) $n^{\circ} 1215 / 2012$ relativo a la competencia judicial, el reconocimiento y la ejecución de resoluciones judiciales en materia civil y mercantil, Reglamento Bruselas I refundido, Ed. Thomson Reuters Aranzadi, Navarra, 2016, pp. 1049-1052. Y también en, A. Dickinson-E. Lein, The Brussels I Regulation Recast, Ed. Oxford, 2015, p. 31.
} 
Art. 125.5 RMUE

"Los procedimientos resultantes de las acciones $y$ demandas contempladas en el artículo 124, con excepción de las acciones de declaración de inexistencia de violación de marca de la Unión, podrán también llevarse ante los tribunales del Estado miembro en cuyo territorio se hubiere cometido el hecho o el intento de violación o en cuyo territorio se hubiera cometido un hecho de los contemplados en el artículo 11, apartado 2."
Art. 7.2 del RB I-bis:

"Una persona domiciliada en un Estado miembro podrá ser demandada en otro Estado miembro: en materia delictual o cuasidelictual, ante el órgano jurisdiccional del lugar donde se haya producido o pueda producirse el hecho dañoso".

21. Con el texto de ambos artículos, y en negrita se señala las similitudes de ambos, se puede apuntar que según el art. 125.5 RMUE los tribunales de marcas del Estado miembro en cuyo territorio se hubiere cometido o pudiere cometerse la violación o intento de violación de los derechos conferidos por la marca europea, en alternativa a los tribunales señalados en la "segunda regla" anterior, la del art. 124 de la misma norma. Pero en este punto la precaución debe activarse, porque estos tribunales sólo son competentes para conocer de los hechos cometidos en el territorio del Estado miembro donde radica ese tribunal, tal como señala el art. 126.2 RMUE. Esto es lo que la mejor doctrina apunta como el "Mosaic Principle" o "Mosaikbetrachtung". En los casos de presunta vulneración de una marca europea por Internet, la expresión "el hecho de violación" debe entenderse en el sentido de que debe considerarse que dichos actos han sido "cometidos" en el territorio en que hayan adquirido su carácter de publicidad y oferta de venta, esto es en el territorio del Estado donde el contenido comercial se ha hecho accesible efectivamente a los consumidores y distribuidores a los que estaba destinado. Carece de relevancia si dicha publicidad y dichas ofertas de venta tuvieron posteriormente el efecto de causar la compra de los productos del demandado (STJUE 5 septiembre 2019, C-172/18, Barnett Waddingham, FD 55 “ Sin perjuicio de la verificación que efectúe el órgano jurisdiccional remitente, de los autos que obran en poder del Tribunal de Justicia y de la cuestión planteada se desprende que mediante la acción por violación de marca ejercitada ante dicho órgano jurisdiccional los demandantes en el litigio principal persiguen la publicidad y las ofertas de venta presentadas por los demandados en un sitio web y en redes sociales solo en la medida en que dicha publicidad y dichas ofertas de venta se destinan a consumidores o distribuidores en el Reino Unido"). Pero además de la "accesibilidad" del contenido en cuestión en un concreto Estado miembro, el TJUE exige que el contenido comercial se dirija a consumidores o distribuidores radicados en dicho Estado miembro: "sólo en la medida en que dicha publicidad y dichas ofertas de venta se destinan a consumidores o distribuidores en el Reino Unido"14.

22. En definitiva, la diferencia en la interpretación entre el art. 125.5 del RMUE y el art. 7.2 del RB I-bis es que en el primero el TJUE exige que se verifique el principio de stream of commerce, también conocido como focalización, aunque no aparezca ese principio en el texto de ninguno de los dos artículos que se mencionan. Esta interpretación que realiza el TJUE de la letra del mismo lo hace de modo diferente de la que realiza en numerosa jurisprudencia sobre el art. 7.2 del RB I-bis, en la cual se puede observar que no exige esa "corriente de comercio", y de este modo se observa en los pronunciamientos del TJUE (STJUE 22 enero 2015, C-441/13, Hejduk, FD 32-33; STJUE 3 octubre 2013, C-170/12, Pinckney, FD 42, STJUE 25 octubre 2011, eDate / Martinez, C-509/09 y C-161/10, FD 46) ${ }^{15}$.

${ }^{14}$ A.-L. Calvo caravaca / J. Carrascosa González, Derecho internacional privado, vol. II, Comares, Granada, edición en preparación. STJUE 5 septiembre 2019, C-172/18, Barnett Waddingham, ECLI:EU:C:2019:674

15 STJUE 22 enero 2015, C-441/13, Hejduk, ECLI:EU:C:2015:28 FD 32-33: “ A este respecto, de la jurisprudencia del Tribunal de Justicia se desprende que, contrariamente al artículo 15, apartado 1, letra c), del Reglamento $\mathrm{n}^{\circ} 44 / 2001$, que fue interpretado en la sentencia Pammer y Hotel Alpenhof (C-585/08 y C-144/09, EU:C:2010:740), el artículo 5, punto 3, de dicho Reglamento no exige que el sitio de Internet controvertido «se dirija al» Estado miembro del órgano jurisdiccional ante el que se ha ejercitado la acción (véase la sentencia Pinckney, EU:C:2013:635, apartado 42). Por consiguiente, para determinar el lugar 
23. El art. 125.5 RMUE no acoge la tesis de la focalización o también conocida como tesis de la actividad dirigida, pero el TJUE sí que la interpreta porque para determinar que existe esa vulneración deben de encontrarse clientes y que usen esa marca por la empresa que dirige sus actividades a ese Estado, esto potencia la eficiencia y la eficacia en el destino de los recursos, y ofrece mayor seguridad jurídica. Esta solución potencia asimismo la comercialización a nivel europeo. Potencia en última instancia el buen funcionamiento del mercado interior europeo, aunque bien, se ha de advertir que esa solución no se observa en la dicción literal de las normas. El TJUE en esta interpretación parece inspirarse en los clásicos del DIPr. que ofrecieron grandes soluciones, como es el caso del abogado CH. Dumoulin, en relación con cuál es la expectativa que tienen las partes, las partes creen que serán competentes los tribunales de los países donde ellos comercian. El abogado parisino sostuvo que para conocer la ley aplicable a los contratos era determinante conocer la voluntad de los contratantes, idea que se puede extender a la competencia judicial internacional ${ }^{16}$.

24. La explicación de por qué no aparece la tesis de la focalización en el art. 7.2 del RB I-bis resulta del lugar que ocupa la propia norma en el Reglamento, este artículo prevé la posibilidad de litigar entre particulares que se encuentran en un mismo nivel de contratación. Esto es se utiliza para determinar la competencia judicial internacional de los órganos jurisdiccionales que atienden a controversias donde no existe una parte débil, considerada así por el legislador europeo, ni tampoco existe un empresario que comercialice a través de Internet en diferentes Estados, y a los que sabe que si dirige su actividad comercial, podrá ser potencialmente demandado en los mismos, como se explica a continuación.

25. Las normas que determinan la competencia judicial internacional en relación con los contratos concluidos por consumidores que se recogen la Sección 4 del Título II del Reglamento Bruselas I-bis presentan matizaciones también. Estas son normas que conforman una excepción al normal funcionamiento de las normas de competencia judicial internacional del RB I bis, esto es, al art. 4 y 7 del mismo Reglamento, tal como apunta la jurisprudencia que se observa en la STJUE de 6 de septiembre de $2012^{17}$.

27. En particular, el art. 17 c) del RB I bis exige la existencia del Stream-of-Commerce "en todos los demás casos, cuando la otra parte contratante ejerza actividades comerciales o profesionales en el Estado miembro del domicilio del consumidor o, por cualquier medio, dirija tales actividades a dicho Estado miembro o a varios Estados miembros, incluido este último, y el contrato esté comprendido en el marco de dichas actividades." Esto es fundamental para evitar una excesiva carga para el profesional que opera a través de Internet, por ejemplo, que su web sea meramente visible en un Estado al que no dirige su actividad. De otro modo, parecería excesivo que el que preste un servicio pueda verse demandado ante los tribunales del Estado miembro del consumidor, con el que contrató por medio electrónico, simplemente por el hecho de que su web fuese visible, y siempre que se demuestre que sus actividades no estaban dirigidas al Estado miembro donde se encuentra domiciliado el consumidor.

de materialización del daño a efectos de establecer la competencia judicial sobre la base del artículo 5, punto 3, del Reglamento $n^{\circ} 44 / 2001$, carece de importancia que el sitio de Internet controvertido en el litigio principal no esté destinado al Estado miembro al que pertenece el órgano jurisdiccional ante el que se ha ejercitado la acción." STJUE 3 octubre 2013, C-170/12, Pinckney, ECLI:EU:C:2013:635, FD 42 "Por lo tanto, contrariamente al artículo 15, apartado 1, letra c), del Reglamento, que ha sido interpretado en la sentencia de 7 de diciembre de 2010, Pammer y Hotel Alpenhof (C-585/08 y C-144/09, Rec. p. I-12527), el artículo 5, punto 3, de dicho Reglamento no exige, en particular, que la actividad controvertida «se dirija al» Estado miembro del órgano jurisdiccional ante el que se ha ejercitado la acción." STJUE 25 octubre 2011, eDate / Martinez, C-509/09 y C-161/10, ECLI:EU:C:2011:685, FD 46: "Por lo tanto, parece que Internet reduce la utilidad del criterio relativo a la difusión, en la medida en que el alcance de la difusión de contenidos publicados en ella es, en principio, universal. Además, no siempre es posible, desde el punto de vista técnico, cuantificar esa difusión con certeza y fiabilidad en relación con un Estado miembro particular ni, por lo tanto, evaluar el daño exclusivamente causado en ese Estado miembro."

${ }^{16}$ Vid. los trabajos de J. Carrascosa González, "Contratos internacionales, prestación característica y la teoría de la Stream-Of Commerce", en A.-L. Calvo Caravaca / P. Blanco-Morales Limones, Globalización y Derecho, Ed. Colex, Madrid, 2003, ISBN: 84-7879-767-X, pp. 87-119. J. BASEDOw, "The communitarisation of the conflict of laws under the treaty of Amsterdam", CMLR, 2000, p. 687 ss. J. BASEDOw El derecho de las sociedades abiertas. Ordenación privada y regulación pública en el conflicto de leyes. Bogotá, Ed. Legis, 2017.

${ }^{17}$ STJUE 6 septiembre 2012, as. C-190/11, Yusufi, FD 26-29. ECLI:EU:C:2012:542 
28. Si la tesis de la mera accesibilidad fuese la acogida en la jurisprudencia del TJUE, se observa que podría generar un efecto negativo en la contratación electrónica y una restricción importante en la comercialización transfronteriza ya que las empresas que no deseen verse sometidas en caso de disputa a la competencia de los tribunales del domicilio del consumidor, ya que el coste de litigación se vería incrementado, además de la inseguridad que genera, optarán por no ofertar sus productos a través de internet en determinados mercados limitando así las posibilidades de elección para el consumidor ${ }^{18}$.

29. Esta situación no sería favorable para la libre prestación de servicios ni fomentaría el impulso del mercado único. Por todo, lo apuntado anteriormente, el TJUE crea en la aplicación el artículo 125.5 RMUE la solución que contempla la focalización. Es una concepción del TJUE, la teoría de la focalización la utiliza para dar respuesta a esta cuestión, para evitar una sobreprotección de los clientes que contraten con estas empresas, y que la simple visibilidad de la web no sea un elemento para atraer la competencia a los tribunales del domicilio del cliente. Se exigirá como elementos extra a la visibilidad de la web que existan clientes o consumidores en el país, para que la competencia de los tribunales del Estado donde se vulnera la marca se pueda determinar ${ }^{19}$.

\section{Ley aplicable}

30. A pesar de que la sentencia que se comenta en este trabajo no trata la cuestión de la Ley aplicable a este caso, se considera interesante destacar en este punto un análisis del Derecho aplicable. La vulneración de una marca da lugar a una obligación extracontractual derivada de una infracción de derechos de propiedad intelectual e industrial, y el instrumento legal que determina la Ley aplicable a esta cuestión es el Reglamento (CE) No 864/2007 del Parlamento europeo y del Consejo de 11 de julio de 2007 relativo a la ley aplicable a las obligaciones extracontractuales («Roma II») ${ }^{20}$. En concreto, el artículo 8 de este Reglamento es el que da la clave para la determinación de la Ley aplicable. ${ }^{21}$

31. El considerando 26 del Reglamento Roma II determina ampliamente qué se debe entender por "derechos de propiedad intelectual e industrial" 22 . El artículo 8 del Reglamento Roma II se refiere al

18 Tal como han expuesto los profesores A. L. Calvo Caravaca/ J. Carrascosa González (Dirs.), Derecho Internacional privado vol.II, op. cit., pp. 817-818. El criterio de la mera accesibilidad es en exceso riguroso con los empresarios que comercian en la UE. También en este sentido lo apunta R. LAfuente SÁnchez, "El criterio del international stream-of-commerce y los foros de competencia en materia de contratos electrónicos celebrados con consumidores", Cuadernos de Derecho Transnacional (octubre 2012), Vol. 4, N² 2, pp. 181.

${ }^{19}$ Sobre los positivos efectos de esta tesis recogida por el TJUE, se puede leer: J. Carrascosa González, "Contratos internacionales, prestación característica y la teoría de la Stream-Of-Commerce", en A.-L. Calvo CARAVACa / P. Blanco-Morales Limones, Globalización y Derecho, Ed.Colex, Madrid, 2003, pp. 87-119; E. Castellanos RuIz. "El concepto de actividad profesional «dirigida» al Estado miembro del consumidor: stream-of-commerce", Cuadernos de Derecho Transnacional CDT, 2012, pp. 70-92; R. LAfuente SÁnchez, "El criterio del International Stream-of-Commerce y los foros de competencia en materia de contratos electrónicos celebrados con consumidores", Cuadernos de Derecho Transnacional CDT, 2012, pp. 177201; V. Pironon, "Dits et non-dits sur la méthode de la focalisation dans le contentieux contractuel et délictuel du commerce électronique", JDI Clunet, 2011, pp. 915-941; A. LóPEz TARrUelLa, "Criterio de "focalización" y "forum delicti commissi" en las infracciones de propiedad industrial e intelectual en Internet", Revista de propiedad intelectual, $\mathrm{n}^{\mathrm{o}}$ 31, 2009, pp. 13-52.

${ }^{20}$ DOUE: http://eur-lex.europa.eu/LexUriServ/LexUriServ.do?uri=OJ:L:2007:199:0040:0049:ES:PDF

${ }^{21}$ Artículo 8 del Reglamento Roma II: "Infracción de los derechos de propiedad intelectual

1. La ley aplicable a la obligación extracontractual que se derive de una infracción de un derecho de propiedad intelectual será la del país para cuyo territorio se reclama la protección.

2. En caso de una obligación extracontractual que se derive de una infracción de un derecho de propiedad intelectual comunitario de carácter unitario, la ley aplicable será la ley del país en el que se haya cometido la infracción para toda cuestión que no esté regulada por el respectivo instrumento comunitario.

3. La ley aplicable con arreglo al presente artículo no podrá excluirse mediante un acuerdo adoptado en virtud del artículo 14."

${ }^{22}$ Considerando 26 del Reglamento Roma II: "En cuanto a las infracciones de los derechos de propiedad intelectual, conviene preservar el principio lex loci protectionis que se reconoce universalmente. A efectos del presente Reglamento, la expresión «derechos de propiedad intelectual» debe ser interpretada como referencia a, por ejemplo, los derechos de autor, los derechos afines, el derecho sui generis de la protección de bases de datos y los derechos de propiedad industrial." 
país "para cuyo territorio" se reclama la protección, por lo tanto, es la Lex Loci Protectionis la que regirá la cuestión de determinar la Ley aplicable a la obligación extracontractual que se deriva de la vulneración de un derecho de propiedad intelectual o industrial.

32. El legislador europeo pretende con esta regulación que sea esa Ley, la Lex Loci Protectionis, la única que regule las obligaciones extracontractuales que derivan de la vulneración de un derecho de propiedad intelectual o industrial. Por lo tanto, la posibilidad de elección de Ley hecha por las partes (artículo 14 del Reglamento Roma II) no se admite en estos supuestos. La Ley que determina el artículo 8 del Reglamento Roma II no se puede exceptuar por acuerdo de las partes.

33. El criterio de la Lex Loci Protectionis se ajusta perfectamente con el carácter territorial que ostentan estos derechos. El principio de territorialidad se respeta con esta solución, porque concuerda la Ley del Estado que ha "creado" el derecho inmaterial con la Ley que regula la posible vulneración del mismo. Se litiga en cada país por la vulneración hecha al derecho inmaterial que ese país protege. Es decir, en esta materia no hay un daño global, lo que existe son vulneraciones o daños a la propiedad intelectual o industrial a la que otorga protección el Estado donde está registrada.

34. Son los convenios internacionales vigentes para cada derecho inmaterial en concreto (marcas, patentes, derechos de autor...) los que determinan la Ley que regula la existencia y contenido de esos derechos. Si no existe Convenio internacional específico, en el caso de España, se aplicará el artículo 10.4 del Código Civil. Este artículo determinará la Ley aplicable a la existencia, contenido y extensión de esos derechos inmateriales, que será también, la Lex Loci Protectionis. Pero el artículo 8 del Reglamento Roma II ha desplazado al artículo 10.4 del Código Civil, en relación con la precisión de la Ley aplicable a la responsabilidad no contractual que surge por la vulneración de un derecho inmaterial.

35. Especial mención se debe hacer de la cuestión de una posible responsabilidad no contractual que derive de la vulneración de uno de estos derechos inmateriales recogidos en instrumentos legales de la Unión Europea (marca comunitaria, dibujos y modelos comunitarios, obtenciones vegetales comunitarias, patentes europeas o cualquier otra que se pueda regular en un futuro). En este supuesto, el artículo 8.2 del Reglamento Roma II $^{23}$ establece que la Ley aplicable será la Ley del país en el que se haya cometido la infracción para toda cuestión que no esté regulada por el respectivo instrumento legal de la Unión Europea. Es decir, en estos casos la Ley aplicable a las obligaciones no contractuales que deriven de la vulneración, por ejemplo, de una marca comunitaria, se regirá por la Ley del país en el que se haya cometido la infracción de ese derecho inmaterial de alcance europeo, es decir, la Lex Loci Delicti Commissi. Con todo lo apuntado, la Ley estatal a la que conduce la aplicación de la norma europea refleja la tesis del principio de proximidad, y como anteriormente se señalaba con la competencia judicial internacional y las enseñanzas de Сн. Dumoulin: el principio de proximidad significa que el contrato debe quedar sujeto a la Ley estatal cuya aplicación al contrato sea más fácilmente previsible por los contratantes. La previsibilidad de que la Ley estatal aplicable será la Ley del Estado en el que la marca ha sido vulnerada cumple con esa función, y respeta las expectativas razonables de las partes, en palabras de P.E. NYGH, se trata de dejarse guiar por "the reasonable expectations of the parties"24.

\footnotetext{
${ }^{23}$ Artículo 8.2 del Reglamento Roma II: "En caso de una obligación extracontractual que se derive de una infracción de un derecho de propiedad intelectual comunitario de carácter unitario, la ley aplicable será la ley del país en el que se haya cometido la infracción para toda cuestión que no esté regulada por el respectivo instrumento comunitario."

${ }^{24}$ En J. CARrascosa GonzÁlez, "Contratos internacionales, prestación característica y la teoría de la Stream-Of Commerce", en A.-L. Calvo Caravaca / P. Blanco-Morales Limones, Globalización y Derecho, Ed.Colex, Madrid, 2003, ISBN: 84-7879767-X, pp. 87-119. Сн. Dumoulin reformula, en su obra Conclusiones de statutis et consuetudinibus localibus (Comentario al Codex de Justiniano, libro primero, título primero, edición de 1681, tomo III, p. 554), la Ley Si Fundus, para evitar su aplicación a casos en los que el lugar de celebración es fortuito: "non de loco contractus fortuiti sede domicilii prout crebrius usuvenit inmobilia non vendi penegre, sed in loco domicilii". P.E. NYGH, "The reasonable expectations of the parties as a guide to the choice of law in contract and in tort", RCADI, 1995, vol.251, pp. 269-400.
} 


\section{Conclusiones}

36. En primer lugar, el correcto funcionamiento del mercado único no se debe ver alterado con obstáculos que restrinjan las libertades de circulación sobre las que se asienta el mismo. Esta es una realidad de la que se debe partir y no es negociable. Ni obstáculos de Derecho público ni obstáculos de Derecho privado deben perturbar el mercado interior. Esa prohibición viene del propio Derecho europeo, y es labor del propio legislador evitar esos obstáculos a las libertades de circulación en las que se basa el mercado único europeo. El TJUE, en numerosa jurisprudencia, prohíbe la existencia de esos obstáculos y los elimina. Los derechos de propiedad intelectual e industrial no pueden ser un obstáculo injustificado a ese mercado único, ni tan siquiera una excepción a esa norma general.

37. Es un dato constatado que, actualmente, las propiedades inmateriales mueven más riqueza que las propiedades materiales. Se trata, sin duda, de un triunfo del "jurista alquimista", capaz de crear riqueza a partir de un puro concepto intelectual. Es el puro concepto elevado a riqueza.

38. Las nuevas tecnologías en general, e Internet en particular han transformado la arquitectura del mundo, la globalización es un hecho en un mundo cada vez más interconectado. Hoy día, con la facilidad de comunicaciones existente, una marca puede ser explotada en todo el mundo al mismo tiempo (Worldwide Explotation). Ahora también es relativamente frecuente que exista vulneración o usurpación de marcas por Internet. Se debe dar respuesta a esos nuevos retos que se les presentan a los juristas del S. XXI, en relación con los tribunales que serán competentes para conocer de esos litigios y de la Ley aplicable a los mismos, como se ha visto. Una vez más, la respuesta a esas cuestiones viene dada por el TJUE en la jurisprudencia que resuelve estos casos. Las normas regulan los casos generales, para dar respuesta a los particulares está el Tribunal, y en estos casos el TJUE.

39. En relación con la determinación de la competencia judicial internacional de los órganos jurisdiccionales de un Estado miembro, el instrumento legal que la determina es el Reglamento Bruselas I bis. El foro general del domicilio del demandado, previsto en el artículo 4 del precitado Reglamento, opera sin ningún problema en estos casos. Sin embargo, en relación con el foro especial por razón de la materia previsto en el artículo 7.2 del Reglamento Bruselas I bis, el TJUE ha arrojado luz sobre los órganos jurisdiccionales competentes del "lugar del daño" que serán los tribunales del Estado miembro de registro de la marca. Se advierte en este punto, que sigue existiendo esa dispersión competencial según sea el objeto del litigio, marca nacional o marca UE, porque como se indicaba el art. 7.2 del Reglamento Bruselas I-bis sigue manteniendo el peligroso criterio de la mera accesibilidad, es decir, el simple hecho de que el sitio web es accesible desde el Estado miembro donde está registrada la marca nacional es suficiente para que el tribunal pueda declararse competente. $Y$ el art. art. 125.5 RMUE, en la lectura que realiza el TJUE en esta sentencia que se comenta, además de esa accesibilidad exige que se encuentren en ese Estado consumidores o distribuidores, esta es la clave y la novedad que aporta la sentencia, porque son estos sujetos los que consumen los productos de esa determinada marca, y son los elementos determinantes que certifican que esa infracción se produce. No simplemente que se pueda acceder a la web del empresario. Y esa es la clave y la novedad que trae la última jurisprudencia europea en relación a esta cuestión, con la STJUE de 5 de septiembre de 2019, C-172/18, AMS Neve Ltd, Barnett Waddingham Trustees, Mark Crabtree vs. Heritage Audio, S.L., Pedro Rodríguez Arribas. El TJUE en esta sentencia parece que la interpretación que realiza del art. 125.5 RMUE es para este supuesto que resuelve y para todos los supuestos que tengan similitudes con el caso tratado, según se desprende de su FJ 55: "Sin perjuicio de la verificación que efectúe el órgano jurisdiccional remitente, de los autos que obran en poder del Tribunal de Justicia y de la cuestión planteada se desprende que mediante la acción por violación de marca ejercitada ante dicho órgano jurisdiccional los demandantes en el litigio principal persiguen la publicidad y las ofertas de venta presentadas por los demandados en un sitio web y en redes sociales solo en la medida en que dicha publicidad y dichas ofertas de venta se destinan a consumidores o distribuidores en el Reino Unido." La publicidad y la oferta de esa marca se debe destinar a los consumidores o distribuidores de ese Estado, donde se vulnera la marca. 
40. En relación a la ley aplicable, se debe subrayar que con el Reglamento Roma II se ha concentrado la ley aplicable a la existencia de ese derecho inmaterial y al daño que pueda derivar de una vulneración del mismo, en una sola ley estatal: la ley del Estado que corresponde al lugar donde el derecho inmaterial se ha (presuntamente) vulnerado. Esta medida facilita la defensa de estos derechos y ahorra costes de litigación a las partes implicadas en el proceso. Evita especular con la ley aplicable, y, por lo tanto, conduce a resultados previsibles y aumenta la seguridad jurídica en un contexto inseguro per se como es el que presenta en las relaciones internacionales en un mundo globalizado.

41. El Derecho internacional privado cumple una vez más su función de regulación y fomento de las relaciones internacionales, porque a mayor seguridad jurídica los particulares potenciarán su actuación en este contexto global. La riqueza circula y el bienestar social aumenta. El Derecho internacional privado proporciona seguridad en el intercambio internacional y lo fomenta, también en la protección que ofrece ante una vulneración de marca UE.

42. La jurisprudencia que crea el TJUE en esta sentencia sería contra legem, sí, de hecho, en este caso el TJUE va más allá de la letra de la norma del art. 125.5 RMUE e introduce la tesis de la focalización donde no aparece literalmente. La finalidad última de esa interpretación quizá tenga un objetivo de reducir los costes económicos de la litigación internacional, con el clásico binomio de conquista de mercados y asunción de los riesgos que conlleva esa conquista. El TJUE asume la tesis de la focalización en el art. 125.5 RMUE probablemente para ser fiel a los principios de proximidad y previsibilidad que inspiran el Reglamento, pero esto plantea otra cuestión, por qué no adopta esa interpretación con el art. 7.2 del RB I bis donde impera la tesis de la mera accesibilidad. El TJUE no ha mostrado voluntad de girar hacia la focalización el art. 7.2 del RB I bis de momento, pero desde mi perspectiva sería de gran utilidad que ofreciese grupos de casos en los que, dependiendo de las circunstancias concretas de los mismos, operase una tesis u otra o una combinación de las dos: la tesis de la focalización y de la accesibilidad.

43. En definitiva, la solución de la focalización creada por el TJUE genera un plus de seguridad jurídica para los empresarios que comercializan en el mercado europeo, sujetos a normas europeas y cuyas controversias se resuelven por el TJUE. La tesis de la focalización le permite prever al empresario una posible demanda en el país en cuyo territorio tiene clientes, sean consumidores o distribuidores. La tesis de la focalización protege en definitiva al sujeto que realiza una actividad y que tiene la voluntad de que esa actividad despliegue sus efectos en un concreto Estado o Estados, es decir, se une la voluntad del sujeto de conquistar un mercado y que en ese mercado existan consumidores o distribuidores de la marca. No solo que desde ese Estado se pueda acceder a la web donde se utiliza la marca europea vulnerada. Tanto la competencia judicial internacional y la ley aplicable al caso debe de ser la que las partes tuviesen "in mente" cuando realizan sus actos de conquista del mercado. 